\title{
The Job Demands-Resources model: An analysis of additive and joint effects of demands and resources
}

\author{
Qiao $\mathrm{Hu}^{\mathrm{a}, *}$, Wilmar B. Schaufeli ${ }^{\mathrm{b}}$, Toon W. Taris ${ }^{\mathrm{b}}$ \\ a Yongkang Nursing School of Zhejiang Province, 321300 Yongkang City, Zhejiang Province, China \\ ${ }^{\mathrm{b}}$ Department of Work and Organizational Psychology, Utrecht University, The Netherlands
}

\section{A R T I C L E I N F O}

Article history:

Received 6 December 2010

Available online 28 December 2010

\section{Keywords:}

Job Demands-Resources model

Additive effect

Moderating effect

Burnout

Engagement

\begin{abstract}
A B S T R A C T
The present study investigated the additive, synergistic, and moderating effects of job demands and job resources on well-being (burnout and work engagement) and organizational outcomes, as specified by the Job Demands-Resources (JD-R) model. A survey was conducted among two Chinese samples: 625 blue collar workers and 761 health professionals. A series of multi-group structural equation modeling analyses supported the two processes proposed by the JD-R model: (1) the stress process that originates from job demands and leads, via burnout, to negative organizational outcomes (turnover intention and low organization commitment); and (2) the motivational process that originates from job resources and leads, via work engagement, to positive organizational outcomes. In contrast to moderating effects, synergistic effects of job demands and job resources on burnout and work engagement were found in both samples. However, after controlling for additive effects of job demands and job resources, these synergistic effects largely disappeared. In conclusion, the hypothesized additive effects of the JD-R model were found but the evidence for additional synergistic and moderating effects was weak.
\end{abstract}

(c) 2010 Elsevier Inc. All rights reserved.

At the heart of occupational health psychology lies the assumption that job characteristics such as job demands and job control affect worker health and well-being. In practice, such effects usually take the form of main effects of these job characteristics on the criterion variables (e.g., Bakker \& Demerouti, 2007). However, from a theoretical perspective it is frequently assumed that job characteristics also jointly affect the outcome variables. For example, Karasek and Theorell's (1990) job demands-control (-support) model proposes that the adverse effects of high demands are buffered by high levels of job control and social support, thus decreasing the adverse effects of high demands on worker health and well-being. Similarly, the more general Job DemandsResources model (Demerouti, Bakker, Nachreiner, \& Schaufeli, 2001) proposes that the combination of high levels of resources and high demands increases the "motivational potential" of jobs, and hence leads to work engagement (Bakker \& Demerouti, 2007). Thus, it is not uncommon in occupational health psychology to examine the effects of job characteristics on health in terms of main effects as well as the joint effects with other work characteristics.

Unfortunately, the magnitude of such moderating joint effects is usually small (Taris, 2006). On the one hand one could argue that these small joint effects are of little importance. However, on the other hand, these small effect sizes could suggest that the conceptualization and measurement of these moderating joint effects is suboptimal. That is, the magnitude of these effects may be underestimated. Psychologists usually examine such moderating joint effects using the framework proposed by Baron and Kenny (1986), in which the multiplication of the standardized raw variables is used as an additional predictor of the study outcomes (cf. Aiken \& West, 1991). However, multiplication of predictor terms may not be the only way to study the joint effects of job characteristics. For example, several alternative approaches focus on the difference between two sets of job characteristics (i.e., a

\footnotetext{
* Corresponding author.

E-mail address: qiaohu2005@yahoo.com.cn (Q.Hu).
} 
synergistic joint effect). For instance, the quadrant approach focuses on the difference between high strain groups of employees and low job strain groups, and their relation with employee health and well-being (Karasek \& Theorell, 1990). Another alternative is the ratio approach advocated by Siegrist (1996) in his Effort-Reward Imbalance (ERI) model, who studied the ratio of "effort" and "rewards" in relation to employee health and well-being. At present it is unclear which of these approaches measuring the joint effects of work characteristics is optimal (i.e., the multiplicative, quadrant or ratio approach). The present study addresses this issue using the Job Demands-Resources (JD-R) model as a theoretical framework and by including two independent Chinese samples.

\section{The Job Demands-Resources model}

The JD-R model proposes that employee well-being is related to a wide range of workplace characteristics that can be conceptualized as either job demands (i.e., the physical, social, or organizational aspects of the job that require sustained physical or psychological effort) or job resources (i.e., those aspects of the job that may reduce job demands, are instrumental to achieve work goals, or promote personal growth, learning and development) (Bakker \& Demerouti, 2007). Excess job demands and lacking job resources exert an energy-draining effect on employees through a stress process, while high levels of job resources are related to positive work outcomes through a motivational process.

There has been considerable empirical support for the stress and motivational processes. For example, working in a demanding job and having few job resources is associated with burnout (Llorens, Bakker, Schaufeli, \& Salanova, 2006), company registered sickness absence (Schaufeli, Bakker, \& van Rhenen, 2009), perceived ill-health (Hakanen, Bakker, \& Schaufeli, 2006), and health complaints (Korunka, Kubicek, \& Schaufeli, 2009). Further, the motivational process links job resources via work engagement with organizational commitment (Llorens et al., 2006), low turnover intention (Schaufeli \& Bakker, 2004), and extra-role performance (Bakker, Demerouti, \& Verbeke, 2004).

In addition to these two additive processes, the JD-R model also assumes two moderating effects, namely that: (1) job resources buffer the potentially negative effects of excessive job demands on employee health and well-being, while (2) highly demanding work situations in combination with high levels of job resources result in higher levels of work engagement (Bakker \& Demerouti, 2007). This agrees with the strain and learning hypotheses of Karasek and Theorell's (1990) JDC model, respectively. Indications have been found for the former moderating effect of job demands and job resources on psychological strain in largescale studies among teachers in higher education (Bakker, Demerouti, \& Euwema, 2005), and home care staff (de Jonge, Le Blanc, Peeters, \& Noordam, 2008), as well as in a study using multiple occupations (Bakker et al., 2004). However, in most cases the moderating effect received only partial support (e.g., Bakker et al., 2005), and the interaction effect between various job demands and job resources is typically weak.

Unlike the JDC model, the JD-R model does not predict an interaction between specific job demands and specific job resources. Rather, an interaction is assumed between an overall, composite indicator of job demands and a similar indicator of job resources. This assumption was supported in a study of Bakker, Demerouti, Taris, Schaufeli, and Schreurs (2003) that used a general indicator for job demands and job resources and found that job resources buffered the impact of job demands on exhaustion, a key dimension of burnout. In the present study, we test the moderating joint effects of job demands and job resources not only with respect to negative work-related outcomes (i.e., burnout), but also with respect to positive work-related outcomes (i.e., work engagement) by using general, composite indicators for job demands and job resources.

\section{Additive, moderating and synergistic effects}

Past investigations on the relation between job demands and job resources using the JD-R model were restricted to additive and moderating joint effects. Kasl (1996) suggested that investigators should go beyond testing models to explore possible alternatives "even if these are not formally part of the model or even part of some broader formulation" (p. 49). We followed this lead by examining synergistic joint effects; that is, we assume that both high demands and low resources are associated with an increased health risk and that a combination of both increases the risk beyond the mere additive effects (Van Vegchel, De Jonge, \& Landsbergis, 2005; Kasl, 1996). In other words, the combined risk of high demands and low resources for burnout is higher than the separate risks of high demands and low resources. A growing number of studies on the JDC-model and the ERI-model use such synergistic joint effects (i.e., the quadrant approach and ratio approach, respectively; Van Vegchel et al., 2005; Siegrist et al., 2004), predicting among others psychiatric disorder (Stansfeld, North, White, \& Marmot, 1995), stress (Calnan, Wadsworth, May, Smith, \& Wainwright, 2004), and sickness absenteeism (Griep, Rotenberg, Chor, Toivanen, \& Landsbergis, 2010). Furthermore, a combination of the ratio approach and the quadrant approach appears to improve the estimated risk of psychiatric disorder, compared to both approaches separately (e.g., Siegrist, 2002; Ota et al., 2005).

Although Siegrist (1996) and Theorell and Karasek (1996) only included a limited number of specific work characteristics in their models (i.e., job demands, job control, effort and reward) their work is relevant for other models, such as the JD-R model. More specifically, Van Vegchel et al. (2005) suggest that an additive effect (i.e., discrepancy form, in which each predictor variable has a linear association with strain, also see Edwards \& Cooper, 1990) implies that job resources represent $a$ standard by which job demands are compared. The moderating effect (i.e., the multiplicative form, in which the combined effect of two predictor variables accounts for an additional proportion of the variance of an outcome variable, beyond their separate main effects) implies that job resources influence the strength of the relation between job demands and strain. Finally, the synergistic form shares characteristics of both additive and interactive forms, in that job resources operate as a standard by which job demands are 
compared and that influence the strength of the relation between job resources and strain. That is, high demands in proportion to low resources are associated with strain. Thus, the additive, moderating and synergistic combinations of job demands and job resources are theoretically and mathematically distinct, and are therefore not interchangeable (Edwards \& Cooper, 1990).

The ratio approach and the quadrant approach are typically used in studies on the ERI-model (Siegrist, 2002) and the JDCmodel (Landsbergis \& Theorell, 2000), respectively. Some researchers claimed that synergistic joint effects are superior compared to additive effects of job demands and job resources (Kasl, 1996). For example, Siegrist (2002) maintained that the effect of the ERI-ratio on employee health and well-being is larger than the separate main effects of effort and reward. Viewed from this perspective, it is important to explore the synergistic joint effect of job demands and job resources on employee well-being.

\section{Study hypotheses}

The current study aimed (1) to test the JD-R model independently in two different samples, using organizational commitment and turnover intention as organizational outcomes; and (2) to examine and compare the additive, moderating, and synergistic effects of job demands and job resources on burnout and work engagement. Based on the notions discussed above, five substantive hypotheses were tested:

Hypothesis 1. Job demands are negatively related to organizational outcomes through their impact on burnout (stress process). That is, burnout mediates the relation between job demands and organizational outcomes.

Hypothesis 2. Job resources are positively related to organizational outcomes through their impact on work engagement (motivational process). That is, engagement mediates the relation between job resources and organizational outcomes.

Hypothesis 3. Job resources buffer the effect of job demands on burnout (moderating effect). More specifically, the relation between job demands and burnout is stronger for employees with few job resources.

Hypothesis 4. Job resources buffer the effect of job demands on work engagement (moderating effect). More specifically, the relation between job demands and work engagement is weaker for employees with many job resources.

Hypothesis 5. The joint effect of high job demands and poor job resources predicts higher burnout and lower work engagement (synergistic effect), irrespective of whether the ratio between demands and resources (ratio approach) or the difference between groups (quadrant approach) is used.

\section{Method}

Sample and procedure

The present study employed data from two samples. Sample 1 comprised 625 blue collar workers of three mechanic factories in China; 348 (56\%) were male and 275 (44\%) female. Their mean age was 31.81 years $(S D=9.16) ; 8.3 \%$ had completed primary education, $84.3 \%$ had a secondary education, and $6.5 \%$ had a college or university education. Questionnaires were distributed by the human resource departments and the survey was accompanied by a letter explaining the general aim of the study, and that emphasized the participants' privacy. The response rate was $73 \%$.

Sample 2 consisted of 761 health professionals from four Chinese hospitals, 545 nurses and 216 doctors; 670 were female ( $88 \%$ ) and 91 male (12\%). Their mean age was 30.80 years $(S D=8.42) ; 25.4 \%$ had a secondary education, $42.9 \%$ had a college education, and $31.7 \%$ had a university education. Questionnaires were handed out by hospital administrators and a similar accompanying letter as in Sample 1 was included. The response rate was $75 \%$.

\section{Measures}

The measures used in the present study had all been included in previous research in Europe, where they showed sufficient reliability and construct validity (e.g., Schaufeli et al., 2009). Table 1 presents the internal consistencies of the scales (Cronbach's $\alpha$ ).

Job demands were assessed by the Chinese version of the Questionnaire on the Experience and Evaluation of Work (QEEW, cf. Van Veldhoven, De Jonge, Broersen, Kompier, \& Meijman, 2002; Zheng, Hu, Xu, \& He, 2010) with a 5-point response scale ranging from 1 ("never") to 5 ("always"). Higher scores indicated higher levels of job demands. The demands included in the present study were: workload (5 items), for example, "Do you have too much work to do?"; emotional demands ( 3 items), for example, "Are you confronted at your work with situations or events that affect you personally?"; physical effort (7 items), for example, "At your work, do you have to lift or move heavy loads?"; and interpersonal conflict (4 items), for example, "How often do you get into arguments with others at work?".

Job resources at work were also assessed by subscales of the Chinese version of the QEEW (Zheng et al., 2010), using the same 5-point answering format. Five job resources were included: job control ( 3 items), for example, "Do you have freedom in carrying out your work activities?"; colleague support (3 items), for example, "Can you count on your colleagues when you come across difficulties in your work?"; supervisory coaching (4 items), for example, "My supervisor knows how to effectively coordinate the 
Table 1

Means (M), standard deviations (SD), internal consistencies (Cronbach's $\alpha$ on the diagonal), and correlations between the study variables for blue collar workers $(n=625$, lower diagonal) and health professionals $(n=761$, upper diagonal).

\begin{tabular}{|c|c|c|c|c|c|c|c|c|c|c|}
\hline & \multicolumn{2}{|c|}{ Blue-collar Workers } & \multicolumn{2}{|c|}{ Health professionals } & \multirow[t]{2}{*}{1} & \multirow[t]{2}{*}{2} & \multirow[t]{2}{*}{3} & \multirow[t]{2}{*}{4} & \multirow[t]{2}{*}{5} & \multirow[t]{2}{*}{6} \\
\hline & $M$ & $S D$ & $M$ & $S D$ & & & & & & \\
\hline 1. Work overload & 2.53 & .85 & 3.29 & .87 & $.75 / .82$ & .50 & .59 & .35 & -.04 & .08 \\
\hline 3. Physical effort & 2.36 & .90 & 2.83 & .95 & .43 & .33 & $.85 / .88$ & .36 & -.11 & -.03 \\
\hline 4. Interpersonal conflicts & 1.52 & .59 & 2.04 & .72 & .29 & .44 & .29 & $.79 / .83$ & -.10 & .01 \\
\hline 5. Job control & 2.17 & .97 & 2.30 & .94 & .03 & .10 & -.15 & .02 & $.68 / .75$ & .27 \\
\hline 6. Colleague support & 2.40 & .77 & 2.86 & .83 & .15 & .16 & .04 & .00 & .30 & $.66 / .82$ \\
\hline 7. Developmental opp. & 2.13 & .90 & 2.34 & .80 & -.05 & .05 & -.20 & -.02 & .52 & .35 \\
\hline 8. Task clarity & 2.98 & .92 & 3.14 & .85 & .06 & .11 & -.09 & .09 & .38 & .24 \\
\hline 9. Supervisor coach & 3.29 & 1.13 & 3.33 & 1.03 & -.18 & -.14 & -.21 & -.12 & .23 & .21 \\
\hline 10. Exhaustion & 2.02 & 1.23 & 3.10 & 1.38 & .35 & .36 & .37 & .27 & -.04 & .03 \\
\hline 11. Cynicism & 1.45 & 1.25 & 2.30 & 1.47 & .17 & .28 & .26 & .22 & -.04 & -.04 \\
\hline 12. Vigor & 3.09 & 1.52 & 2.70 & 1.39 & .01 & -.01 & -.10 & -.09 & .15 & .07 \\
\hline 13. Dedication & 3.03 & 1.52 & 2.85 & 1.39 & -.01 & -.04 & -.15 & -.16 & .19 & .15 \\
\hline 14. Absorption & 2.74 & 1.53 & 2.33 & 1.48 & .01 & .01 & -.15 & -.11 & .22 & .09 \\
\hline
\end{tabular}

Note: correlations of at least .08 (for the blue collar workers) and .07 (for the health professionals) are significant at $p<.05$.

tasks and activities of our team"; learning opportunities (4 items), for example, "I can develop myself sufficiently within my company"; and task clarity (5 items), for example, "Do you know exactly what areas you are responsible for and which areas are not your responsibility?".

Burnout was assessed with the exhaustion and cynicism subscales of the Chinese version (Hu \& Schaufeli, 2011) of the Maslach Burnout Inventory-General Survey (MBI-GS; Schaufeli, Leiter, Maslach, \& Jackson, 1996). Exhaustion was assessed with five items (e.g., "I feel used up at the end of the workday") and cynicism with four items (e.g., "I have become less enthusiastic about my work"). All items were scored on a 7-point frequency rating scale ranging from 0 ("never") to 6 ("daily"). High scores on the exhaustion and cynicism subscales are indicative of burnout.

Work Engagement was assessed with the Chinese version (Zheng et al., 2010) of the Utrecht Work Engagement Scale (UWES-9; Schaufeli, Bakker, \& Salanova, 2006). The UWES-9 taps three underlying dimensions, which are all measured with three items: vigor (e.g., "At my work, I feel bursting with energy", dedication (e.g., "My job inspires me"), and absorption (e.g., "I get carried away when I am working"). All items are scored on a 7-point rating scale ranging from 0 ("never") to 6 ("daily"). High scores on all three dimensions indicate high levels of work engagement.

Organizational outcomes were assessed by two scales: organizational commitment and turnover intention, using the Chinese version of the QEEW (Zheng et al., 2010). Organization commitment was assessed by 5 items (e.g., "I feel like 'a member of the family' at my company/hospital") and turnover intention by 4 items (e.g., "I think about changing my job" - reversed). Both scales were scored on a 5-point rating scale ranging from (1) "never" to (5) "always".

Data analyses

Table 1 provides the means, coefficient alphas, and correlation coefficients of the study variables. As this table shows, the internal stability of all scales was acceptable, with virtually all alphas exceeding the threshold value of .70. The hypotheses were tested using Structural Equation Modeling techniques as implemented in the AMOS (Arbuckle, 2003) computer program. We performed multi-group analyses to assess the invariance of the estimated parameters across both samples (Byrne, 2001). Maximum likelihood estimation was used and the input for each analysis was the covariance matrix. To test the hypotheses, several nested models were compared by means of the $\chi^{2}$ difference test. In addition, absolute and relative indices were computed to assess the goodness-of-fit of the models. The absolute goodness of fit indices were: (1) the $\chi^{2}$ goodness of fit statistic; (2) the Root Mean Square Error of Approximation (RMSEA); and (3) the Goodness of Fit Index (GFI). Non-significant values of $\chi^{2}$ indicate that the hypothesized model fits the data. RMSEA values of .08 and lower indicate an acceptable fit and values of .10 and higher should lead to model rejection (Byrne, 2001). As recommended by Marsh, Balla, and Hau (1996), the following relative goodness of fit indices were computed: (1) Normed Fit Index (NFI); (2) Incremental Fit Index (IFI); (3) Comparative Fit Index (CFI); and (4) Tucker-Lewis Index (TLI). As a rule of thumb, values of .90 or higher indicate good fit for all three relative fit indices (Byrne, 2001).

\section{Results}

\section{Additive effects}

Firstly, the two processes (i.e., the stress process and the motivational process; Hypotheses 1 and 2, respectively) as proposed by the JD-R model were investigated. The basic JD-R model $\left(\mathrm{M}_{1}\right)$ was tested including two indirect paths from job demands to 


\begin{tabular}{|c|c|c|c|c|c|c|c|c|c|}
\hline 7 & 8 & 9 & 10 & 11 & 12 & 13 & 14 & 15 & 16 \\
\hline-.07 & -.02 & .02 & .49 & .36 & -.06 & -.13 & -.07 & -.11 & -.09 \\
\hline-.08 & -.03 & -.06 & .45 & .37 & -.07 & -.12 & -.06 & -.11 & -.12 \\
\hline-.18 & -.12 & -.05 & .52 & .45 & -.19 & -.25 & -.21 & -.22 & -.18 \\
\hline-.14 & -.09 & -.11 & .35 & .35 & -.10 & -.15 & -.11 & -.17 & -.19 \\
\hline .43 & .32 & .14 & -.17 & -.19 & .20 & .23 & .22 & .24 & .05 \\
\hline .36 & .34 & .23 & -.11 & -.19 & .29 & .29 & .27 & .26 & .05 \\
\hline $.73 / .81$ & .50 & .24 & -.33 & -.34 & .36 & .39 & .38 & .43 & .17 \\
\hline .41 & $.73 / .80$ & .36 & -.21 & -.30 & .30 & .33 & .30 & .37 & .11 \\
\hline .38 & .38 & $.87 / .94$ & -.09 & -.21 & .16 & .18 & .14 & .23 & .15 \\
\hline-.15 & -.06 & -.23 & $.80 / .87$ & .79 & -.27 & -.35 & -.26 & -.35 & -.25 \\
\hline-.14 & -.13 & -.26 & .68 & $.79 / .88$ & -.38 & -.49 & -.35 & -.45 & -.36 \\
\hline .28 & .27 & .19 & -.14 & -.23 & $.75 / .82$ & .82 & .74 & .49 & .21 \\
\hline .37 & .31 & .27 & -.20 & -.28 & .75 & $.76 / .85$ & .77 & .56 & .27 \\
\hline .31 & .29 & .23 & -.14 & -.21 & .68 & .75 & $.75 / .84$ & .51 & .26 \\
\hline
\end{tabular}

organizational outcomes via burnout, and from job resources to organizational outcomes via work engagement. Basically, this model assumes full mediation through burnout (Hypothesis 1) and work engagement (Hypothesis 2), respectively. In addition, as postulated by the JD-R model, job demands and job resources, as well as burnout and engagement were allowed to correlate. The results presented in Table 2 show that the fit across both samples was not acceptable, with NFI and TLI slightly below their criterion value of .90. Next, we tested the partial mediating role of burnout and work engagement by adding to $M_{1}$ two direct paths connecting job demands and job resources to organizational outcomes, respectively ( $\mathrm{M}_{1 \text {-alternative }}$. The fit to the data of $\mathrm{M}_{1 \text {-alternative was superior to }}$ that of $\mathrm{M}_{1}\left(\Delta \chi^{2}(4)=52.37, p<.001\right)$, but the direct path from job demands to organizational outcomes was neither significant for blue collar workers $(\gamma=.03, n s)$ nor for health professionals $(\gamma=.10, n s)$. Deleting this path $\left(\mathrm{M}_{1 \text {-modified }}\right)$ did not result in a significant deterioration of the fit between model and data $\left(\Delta \chi^{2}(2)=1.62, n s\right)$. Still, the fit of $\mathrm{M}_{1 \text {-modified, }}$ which included a direct path from job resources to organizational outcomes, was not acceptable because values for NFI and TLI were still slightly below .90 .

Therefore, in the next step we tested an alternative model that included two additional cross-links; that is, paths from job resources to burnout and from job demands to engagement $\left(\mathrm{M}_{2}\right)$. The former was included in the original JD-R model, whereas the latter was added more recently (Bakker \& Demerouti, 2007). As Table 2 shows, the fit to the data of $\mathrm{M}_{2}$ is superior to that of $\mathrm{M}_{1 \text {-modified }}\left(\Delta \chi^{2}(4)=135.16, p<.001\right)$, with all fit indices of $\mathrm{M}_{2}$ meeting their corresponding criteria.

As two different samples were involved, equivalence of $\mathrm{M}_{2}$ across samples was tested of (a) the factor loadings, (b) regression weights, and (c) both the factor loadings and regression weights of $\mathrm{M}_{2}$. Results revealed that the three constrained models had a good fit to the data (see Table 2). However, chi-square difference tests showed the model that allowed all parameters to vary across samples ( $\left.\mathrm{M}_{2 \text {-unconstrained }}\right)$ to fit significantly better to the data than the three constrained models, although the differences were only small in terms of the change of absolute and relative indices. Chen (2007) proposed that changes of less than .01 (for CFI) and less than .015 (for RMSEA) are practically unimportant for tests of measurement weight invariance and measurement residual invariance, respectively. Because the change of fit indices is negligible (these range from -.004 to .001 in the three constrained models as compared with the unconstrained model $\mathrm{M}_{2}$ ), it implies that relations among the variables are invariant across two samples.

The parameter estimates for $\mathrm{M}_{2}$ are shown in Fig. 1. All relations in the model are significant and in the expected direction, except for the association between job demands and job resources $(r=.04, n s)$ in Sample 1. As expected, the paths from job

Table 2

Fit indices of the additive models (Multi-group analysis).

\begin{tabular}{|c|c|c|c|c|c|c|c|c|}
\hline Model & $\chi^{2}$ & $d f$ & CFI & NFI & TLI & GFI & RMSEA & $\Delta \chi^{2}$ \\
\hline Null & 8769.00 & 240 & - & - & - & .44 & .16 & \\
\hline $\mathrm{M}_{1}$ & 1003.20 & 196 & .91 & .89 & .89 & .92 & .06 & \\
\hline $\mathrm{M}_{1 \text {-alternative }}$ & 950.83 & 192 & .91 & .89 & .89 & .92 & .05 & $52.37(4)^{* * *}$ \\
\hline $\mathrm{M}_{1 \text {-modified }}$ & 952.45 & 194 & .91 & .89 & .89 & .92 & .05 & $1.62(2) n s$ \\
\hline $\mathrm{M}_{2}$ (unconstrained model) & 817.29 & 190 & .93 & .91 & .91 & .93 & .05 & $135.16(4)^{* * *}$ \\
\hline Equal factor loadings & 846.16 & 201 & .92 & .91 & .91 & .93 & .05 & $28.87(11)^{* *}$ \\
\hline Equal regression weights & 845.85 & 197 & .92 & .91 & .91 & .93 & .05 & $28.56(7)^{* * *}$ \\
\hline
\end{tabular}

Note. $\chi^{2}=$ chi-square; $d f=$ degrees of freedom. $C F I=$ Comparative Fit Index; NFI = Normed Fit Index; TLI = Tucker-Lewis Index; GFI $=$ Goodness-of-Fit Index; RMSEA $=$ Root Mean Square Error of Approximation. ${ }^{* *} p<.01,{ }^{* * *} p<.001$. 


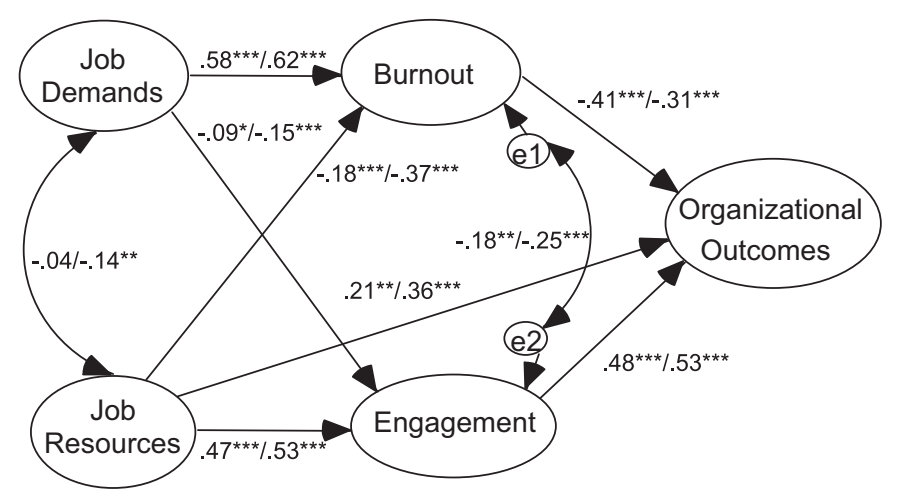

Fig. 1. Standardized path coefficients of the final model $\left(\mathrm{M}_{2}\right)$ in blue collar workers $(n=625)$ and health professionals $\left(n=761 ;{ }^{*} p<.05,{ }^{* *} p<.01,{ }^{* * *} p<.001\right)$.

demands to burnout were positive and significant $(\gamma=.58$ and $.62, p<.001$ ), whereas those from burnout to organizational outcomes were negative and significant $(\gamma=-.41$ and $-.31, p<.001)$. The indirect effects of job demands on organizational outcomes were smaller than the direct effects, but significant $\left(\gamma_{\text {indirect }}=-.28\right.$ and $\left.-.27, p<.001\right)$. Further, the paths from job resources to work engagement $(\gamma=.47$ and $.53, p<.001)$ and from engagement to organizational outcomes were positive and significant ( $\gamma=.48$ and $.53, p<.001$, respectively).

Thus, the higher the perceived job demands, the higher the employee's level of burnout, the stronger their turnover intention, and the lower their organizational commitment (Hypothesis 1 supported). On the other hand, the more job resources, the higher the employee's level of work engagement, the lower their turnover intention, and the stronger their organization commitment. Unexpectedly, job resources had a direct positive relation with organizational outcomes, indicating that work engagement only partially mediated the relation between job resources and organizational outcomes (Hypothesis 2 partially supported). In addition, fewer job resources were related to more burnout $(\gamma=-.18$ and $-.37, p<.001)$, whereas job demands were weakly negatively related to work engagement $(\gamma=-.09, p<.05$ and $\gamma=-.15, p<.001)$.

\section{Moderation effects}

To test Hypotheses 3 and 4, a moderated structural equation modeling (MSEM) analysis was performed. We tested a model that included three exogenous latent variables: job demands, job resources, and their interaction. For reasons of parsimony we limited the number of indicators for job demands and job resources to two by using a parcel analyses (Floyd \& Widaman, 1995). That is, first two separate principal components factor analyses for the four job demands and the five job resources were conducted in the samples of blue collar workers and health professionals, respectively. A varimax rotation revealed a similar result in both samples. More specifically, two job demands (i.e., workload and physical effort) converged into one demand component, whereas emotional demands and interpersonal conflicts converged into a second demand component. Moreover, three job resources (i.e., job control, colleague support, and learning and development opportunity) converged into one resource component, whereas task clarity and supervisor coaching converged into a second component. Thus, instead of including four job demands and five job resources, two parcels consisting of composite scores of various scales which constituted a particular component were included as indicators of the latent job demands and job resources factors.

First, the additive effect of the parceling job demands and parceling job resources on burnout and work engagement revealed a good fit in multigroup analysis $\left(\chi^{2}=408.29, \mathrm{GFI}=.95, \mathrm{RMSEA}=.06, \mathrm{NFI}=.94, \mathrm{TLI}=.92, \mathrm{CFI}=.95\right)$. Next, a MSEM model was conducted. To prevent multi-collinearity in MSEM, the indicators were mean-centered (cf. Aiken \& West, 1991; Jaccard, Wan, \& Turrisi, 1990). The four indicators of the latent interaction factor were the multiplicative product of the factor scores of the two job demands indicators and the two job resources indicators.

A significant joint effect, as assumed by Hypotheses 3 and 4, exists if the coefficient of the path from the latent interaction factor to burnout or work engagement is statistically significant. The result of the multigroup MSEM analysis showed that the model as depicted in Fig. 2 did not fit the data well, $\chi^{2}=1243.22, \mathrm{GFI}=.91$, RMSEA $=.07, \mathrm{NFI}=.86$, TLI $=.84$, and CFI $=.88$. Only the path-coefficient linking the interaction term to burnout was significant to $(\gamma=-.08, \mathrm{p}<.05)$ among health professionals ( see Fig. 2). Thus, whereas Hypothesis 3 was confirmed in health professionals, Hypothesis 4 was rejected in both samples. Apparently, job resources modify the negative effect of job demands on burnout only in health professionals but not in blue collar workers.

To further examine the nature of the significant interaction effect, a graphical representation was produced by using the procedure of simple slope analyses (Aiken \& West, 1991). Subgroups were created of those who scored one standard deviation below $(n=128)$ and above $(n=126)$ the mean on the composite measure of job resources. Fig. 3 shows the interaction between demands and resources with regards to two burnout indicators (i.e., exhaustion and cynicism) in health professionals. As expected, high job demands coincided with high levels of burnout, but only when job resources were low. 


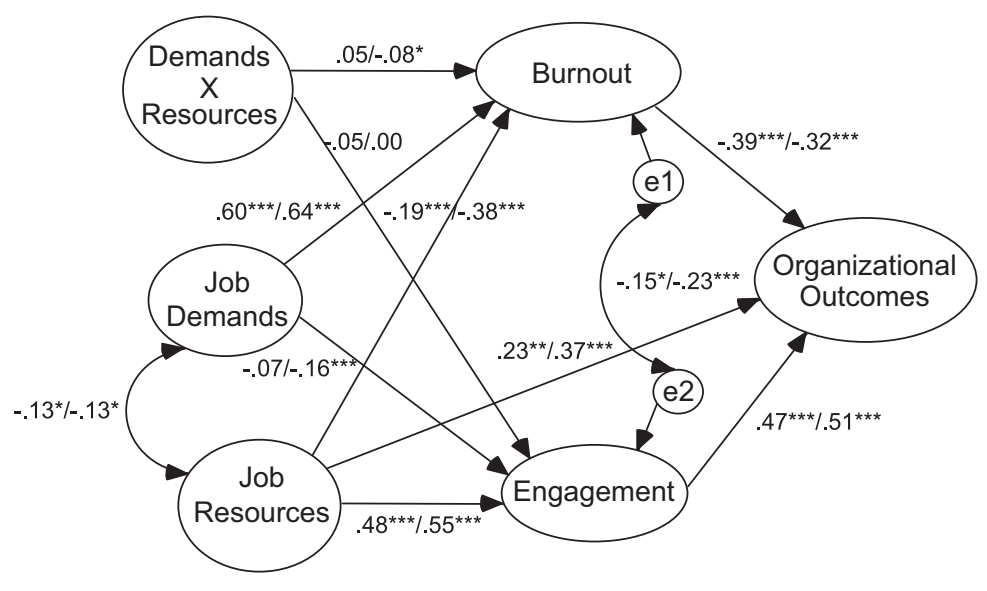

Fig. 2. Standardized path coefficients of the MSEM-analysis in blue collar workers $(n=625)$ and health professionals $(n=761) ;{ }^{*} p<.05,{ }^{* * *} p<.001$.

\section{Synergistic effects}

The ERI ratio was computed for every respondent following the formula $e /(r \times c)$ where $e$ is the sum score of the job demands, $r$ is the sum-score of the job resources and $c$ corrects for different numbers of items in the nominator and denominator (Siegrist et al., 2004). As there are 19 job demands items and 19 job resources items in our study $c$ was 1 . Next, we constructed tertiles of ERI-ratios to identify a high-risk group in terms of the upper tertile, whereby the lowest tertile indicated the most favorable work condition (e.g., Calnan et al., 2004). In order to distinguish the odds ratios that result from logistic regression, we dubbed the ERI ratios method in our study "DR ratios".

The quadrant approach was modeled by assigning employees who scored above the median on job demands as well as below the median on job resources to the high job strain group. Employees who simultaneously scored below the median on job demands and above the median on job resources were assigned to the non-job strain group. The remaining employees were assigned to the intermediate job strain group. Logistic regression analyses were performed; the associations were estimated by means of an adjusted odds ratio.

Taking the low demands-high resources group for a reference, Table 3 shows the synergistic effects of job demands and job resources on burnout and work engagement by using DR ratios as well as the quadrant approach. The associations between job strain (i.e., low job demands and high job resources) on the one hand, and burnout and engagement on the other hand were significant in blue collar workers as well as in health professionals (i.e., ORs varied from 2.40 to 27.90 for burnout and from .12 to .44 for work engagement). Moreover, these associations were consistently in the expected direction (i.e., high job demands and low job resources were associated with more burnout and lower work engagement, Hypothesis 5 confirmed).

Interestingly, DR ratios were superior in predicting burnout and work engagement as compared to the quadrant approach. For the high risk group (i.e., the group with high demands and low resources) the risk of burnout for health professionals was higher

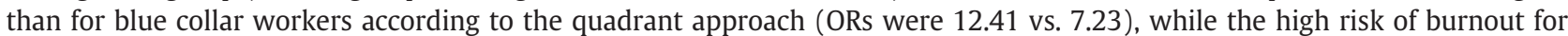
health professionals was lower than for blue collar workers according to the DR ratios (ORs were 14.76 vs. 27.90). In contrast with burnout, the reversed effect of the high risk group on low work engagement for health professionals was higher than that of workers, irrespective of using DR ratios or the quadrant approach (ORs were .12 vs. .19 and .16 vs. .32).

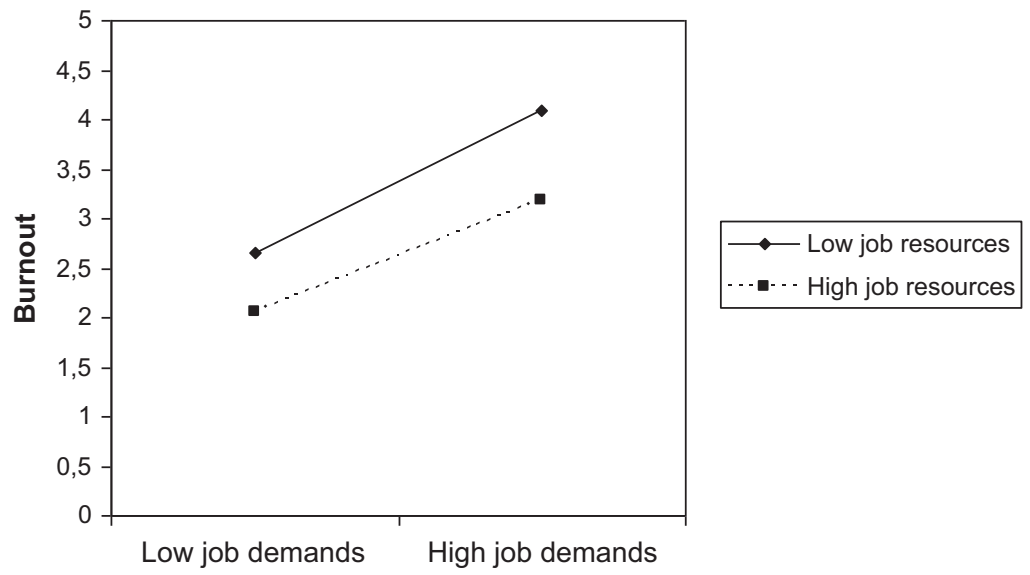

Fig. 3. The interaction effect of job resources on and job demands on burnout among health professionals $(n=761)$. 
Table 3

Logistic regression of burnout and work engagement on job demands and job resources for by using DR ratios and the quadrant approach.

\begin{tabular}{|c|c|c|c|c|c|c|c|c|}
\hline & \multicolumn{4}{|c|}{ Burnout } & \multicolumn{4}{|c|}{ Engagement } \\
\hline & \multicolumn{2}{|c|}{ Blue collar workers } & \multicolumn{2}{|c|}{ Health professionals } & \multicolumn{2}{|c|}{ Blue collar workers } & \multicolumn{2}{|c|}{ Health professionals } \\
\hline & OR & $95 \% \mathrm{CI}$ & OR & $95 \% \mathrm{CI}$ & OR & $95 \% \mathrm{CI}$ & OR & $95 \% \mathrm{CI}$ \\
\hline \multicolumn{9}{|l|}{ DR ratios } \\
\hline Low demands and high resources & 1.0 & & 1.0 & & 1.0 & & 1.0 & \\
\hline Intermediate demands and resources & 12.27 & $2.97-50.73$ & 2.40 & $1.34-4.32$ & .28 & $.17-.46$ & .37 & $.25-.53$ \\
\hline High demands and low resources & 27.90 & $6.34-122.71$ & 14.76 & $8.06-27.01$ & .19 & $.09-.46$ & .12 & $.07-.22$ \\
\hline \multicolumn{9}{|l|}{ Quadrant approach } \\
\hline Low demands and high resources & 1.0 & & 1.0 & & 1.0 & & 1.0 & \\
\hline Intermediate demands an resources & 3.69 & $2.01-6.77$ & 3.60 & $1.98-6.54$ & .44 & $.29-.66$ & .40 & $.28-.58$ \\
\hline High demands and low resources & 7.23 & $3.84-13.59$ & 12.41 & $6.73-22.88$ & .32 & $.19-.54$ & .16 & $.09-.27$ \\
\hline
\end{tabular}

Note: ORs above 1.0 indicate positive effects, and ORs below 1.0 indicate negative effects. All $p s<.01$.

In the next step we controlled for the additive effects of job demands and job resources in the prediction of burnout and engagement by using DR ratios and the quadrant approach. The results of the hierarchical logistic regression analysis (cf. Table 4) showed that the odds ratios decreased dramatically. The associations between job strain (i.e., high job demands and low job resources) on the one hand, and burnout and engagement on the other hand, were non-significant in blue collar workers as well as in health professionals when the quadrant approach was used, while the associations between high DR ratio groups (i.e., high job demands and low job resources) on the one hand, and burnout and engagement were weak or non-significant in both workers and health professionals. Further analysis revealed that $83.4 \%$ of the high strain health professionals shared the joint distribution with those with high DR ratios, while 78.0\% low job strain health professionals shared the joint distribution with those with low DR ratios; $91.9 \%$ high job strain workers shared the joint distribution with the workers with high DR ratios, while $85.9 \%$ low job strain workers shared the joint distribution with those with low DR ratios.

\section{Discussion}

The present study evaluated the Job Demands-Resources (JD-R) model by - for the first time - incorporating additive, moderating and synergistic effects into the model. First, the results confirmed, for the first time in China, the stress and motivational processes as assumed by the JD-R model (Bakker \& Demerouti, 2007). Consistent with Hypothesis 1, burnout fully mediated the relation between job demands and organizational outcomes, for both blue collar workers and health professionals. Moreover, job resources were negatively associated with burnout. This means that high job demands and lacking job resources exhaust employees' energy resources and may therefore lead to burnout, which in turn, may foster turnover intentions and poor organizational commitment. Similarly and in support of Hypothesis 2, work engagement mediated the relation between job resources and organizational outcomes in both samples. Yet, this mediation effect, that is compatible with the motivational process of the JD-R model, is only partial in nature. That is, in both samples also a significant direct, positive effect of job resources on organizational outcomes was observed. This agrees with previous findings. For example, job resources were positively and significantly related to organizational commitment in Dutch and

Table 4

Hierarchic logistic regression of burnout and work engagement on job demands and job resources by using DR ratios and the quadrant approach.

\begin{tabular}{|c|c|c|c|c|c|c|c|c|}
\hline & \multicolumn{4}{|l|}{ Burnout } & \multicolumn{4}{|c|}{ Engagement } \\
\hline & \multicolumn{2}{|c|}{ Blue collar workers } & \multicolumn{2}{|c|}{ Health professionals } & \multicolumn{2}{|c|}{ Blue collar workers } & \multicolumn{2}{|c|}{ Health professionals } \\
\hline & OR & $95 \% \mathrm{CI}$ & OR & $95 \% \mathrm{CI}$ & OR & $95 \%$ CI & OR & $95 \% \mathrm{CI}$ \\
\hline \multicolumn{9}{|l|}{ Step 1} \\
\hline Job demands & $3.88^{* * *}$ & $2.63-5.73$ & $5.53^{* * *}$ & $3.75-8.17$ & $.65^{*}$ & $.44-.94$ & $.60^{* *}$ & $.42-.85$ \\
\hline Job resources & $.65^{*}$ & $.44-.96$ & $.44^{* * *}$ & $.44-.96$ & $2.14^{* * *}$ & $1.48-3.09$ & $3.80^{* * *}$ & $2.66-5.45$ \\
\hline Low demands and high resources & 1.0 & & 1.0 & & 1.0 & & 1.0 & \\
\hline Intermediate & $8.44^{* *}$ & $1.72-41.46$ & $7.07^{* * *}$ & $2.94-16.97$ & $.35 *$ & $.14-.92$ & $.19^{* * *}$ & $.08-.43$ \\
\hline High demands and low resources & $6.42^{*}$ & $1.49-27.67$ & 1.50 & $.75-2.98$ & $.38^{* *}$ & $.21-.68$ & $.43^{* *}$ & $.26-.71$ \\
\hline \multicolumn{9}{|l|}{ Step 2 quadrant approach } \\
\hline Low demands and high resources & 1.0 & & 1.0 & & 1.0 & & 1.0 & \\
\hline Intermediate & - & - & .00 & .00 & - & - & $.04^{*}$ & $.00-1.00$ \\
\hline High demands and low resources & 1.45 & $.96-2.20$ & .00 & .00 & .79 & $.54-1.16$ & $.19^{*}$ & $.04-9.7$ \\
\hline
\end{tabular}

Note: ORs above 1.0 indicate positive effects, and ORs below 1.0 indicate negative effects.

$* p<.05$.

** $p<.01$.

*** $p<.001$. 
Spanish white collar employees (Llorens et al., 2006) and Chinese blue collar workers (Hu \& Schaufeli, submitted for publication). Our study found that job demands were negatively associated with work engagement, although this effect was rather weak compared to that of job resources. In fact, Llorens et al. (2006) also found that job demands were negatively related with work engagement. Apparently, in our samples demands were not perceived as a challenge but rather as burdensome.

The joint additive effects of job demands and job resources on burnout and work engagement agree with the strain hypothesis of the JDC-model (Theorell \& Karasek, 1996). That is, jobs characterized by chronically high imposed demands and insufficient job resources may induce strain (burnout) and reduce well-being (engagement). Unfortunately, the JDC-model uses a rather restricted definition of job demands and job resources that only includes quantitative job demands (e.g., work overload and time pressure), and two job resources (i.e., job control and social support). Our study shows that a much broader range of job stressors and job resources leads to effects that are in line with predictions from the JDC-model.

Another focus in our study is whether job resources interact with job demands in influencing the stress and motivational processes. Specifically, the combination of high job demands and lack of resources was related to burnout (Hypothesis 3 ). However, the combination of high job demands and low job resources that produced high burnout levels was very weak $(\gamma=$ $-.08, p<.05$ ). In our study, the combination of high job demands and low job resources produced the highest level of burnout, but only in health professionals. As health care professionals are usually very dedicated to their work and highly intrinsically motivated, a combination of high demands and lacking resources is obviously more psychologically detrimental than in blue collar workers, who usually are less dedicated and more externally motivated (cf. Dickerson, Brewer, Kovner, \& Way, 2007).

A more general explanation why Hypothesis 3 was not unequivocally supported is that our job demands and job resources did not match very well. It has been suggested that only when specific demands match with specific resources from the same domain, they may produce a joint effect on a specific strain from that same domain (Daniels \& De Jonge, 2010). However, the present study included composite demands and resources, which might have obscured the differential impact of specific components from various domains (Van den Tooren \& De Jonge, 2008).

Furthermore, there may not be a simple interactive effect formula for the joint effects of job demands and job resources on wellbeing. For example, the interactive effect of cognitive job demands and cognitive job resources to learning motivation was non-significant in the informatics (Van de Ven, Vlerick, \& De Jonge, 2008). Similarly, a study of de Jonge et al. (2008) found that the interactive effect of emotional demands (i.e., being confronted with dying or aggressive patients) and emotional job resources on emotional exhaustion was non-significant in health care workers. Indeed, in a review paper about the interactive effect of job demands and job resources, Taris (2006) showed that only 9 out of 90 tests performed provide support for this interaction effect. That means that we should look for new methods to explore the relation between special domain-oriented job demands and special domain-oriented job resources. It follows that in future research, on the one hand the impact of specific, field-oriented demands and resources on outcomes should be investigated, while on the other hand new methodologies on the relation between job demands and job resources should be explored.

Neither the DR ratios nor the quadrant approach supported synergistic effects of job demands and job resources on burnout and work engagement in this study. It is important to note that the predictive power of DR ratios was superior to that of the quadrant approach. Employees experiencing high job demands and low job resources showed higher risks of burnout and reduced work engagement than those in more favorable work conditions. However, after controlling for the additive effects of job demands and job resources, the predictive power of both approaches decreased sharply. Apparently, the synergistic effect on burnout and engagement adds little explanatory power beyond that of the additive effect of job demands and job resources. This is in accordance with Preckel, Meinel, Kudielka, Haug, and Fischer (2007) who showed that the ERI ratio does not provide more information than the separate use of effort and reward.

\section{Strengths and weaknesses}

The strengths of our study are related to the fact that we used a comprehensive methodology not commonly used in occupational psychology (i.e., additive effects, mediated effects as well as synergistic effects). In addition, this is the first study to apply these various types of joint effects in the context of the JD-R model. Furthermore, we observed basically the same results in the two different occupational groups (i.e. blue collar production workers and highly qualified health care professionals) for the additive effects, moderating effects, and synergistic effects. Finally, whereas previous research on the JD-R model used exclusively European samples (from the Netherlands, Spain, Greece, Finland, and Austria), our study applied the model for the first time outside Europe in China, underlining the model's potential in cross-cultural settings.

Some limitations of the study need to be addressed. The first one is its cross-sectional design, which means that no causal inferences can be made. However, other longitudinal studies suggested causal relations as specified by the JD-R model (e.g., Salanova, Schaufeli, Xanthoupoulou, \& Bakker, 2010). Another limitation was that the study relied solely on self-report measures, thus, our measures may have been subject to subjective bias on the part of samples. This may be resolved in further studies by including objective measures, such as actual turnover and sickness absence.

Final note

Our results unequivocally support the additive effects of job demands and job resources on burnout and work engagement. However, evidence for moderating and synergistic effects of job demands and job resources on burnout and work engagement was hardly found in this study. 


\section{References}

Aiken, L. S., \& West, S. G. (1991). Multiple regression: Testing and interpreting interactions. Newbury Park, CA: Sage.

Arbuckle, J. L. (2003). AMOS 5.0 (computer software). Chicago, Ill: SPSS.

Bakker, A. B., \& Demerouti, E. (2007). The job demands-resources model: State of the art. Journal of Managerial Psychology, 22, 309-328.

Bakker, A. B., Demerouti, E., \& Euwema, M. C. (2005). Job resources buffer the impact of job demands on burnout. Journal of Occupational Health Psychology, 10, $170-180$.

Bakker, A. B., Demerouti, E., Taris, T. W., Schaufeli, W. B., \& Schreurs, P. J. G. (2003). A multigroup analysis of the Job Demands-Resources Model in four home care organizations. International Journal of Stress Management, 10, 16-38.

Bakker, A. B., Demerouti, E., \& Verbeke, W. (2004). Using the Job Demands-Resources model to predict burnout and performance. Human Resource Management, $43,83-104$.

Baron, R. M., \& Kenny, D. A. (1986). The moderator-mediator variable distinction in social psychological research: Conceptual, strategic, and statistical considerations. Journal of Personality and Social Psychology, 51, 1173-1182.

Byrne, B. M. (2001). Structural equation modeling with AMOS: Basic concepts, applications and programming. Mahwah, NJ: Erbaum.

Calnan, M., Wadsworth, E., May, M., Smith, A., \& Wainwright, D. (2004). Job strain, effort-reward imbalance and stress at work: Competing or complementary models? Scandinavian Journal of Public Health, 32, 84-93.

Chen, F. F. (2007). Sensitivity of goodness of fit indices to lack of measurement invariance. Structural Equation Modeling, 14, 464-504.

Daniels, K., \& De Jonge, J. (2010). Match-making and match-breaking: Exploring the nature of match within and around job design. Journal of Occupational and Organizational Psychology, 83, $1-16$.

de Jonge, J., Le Blanc, P. M., Peeters, M. C. W., \& Noordam, H. (2008). Emotional job demands and the role of matching job resources: A cross-sectional survey study among health care workers. International Journal of Nursing Studies, 45, 1460-1469.

Demerouti, E., Bakker, A. B., Nachreiner, F., \& Schaufeli, W. B. (2001). The Job Demands-Resources model of burnout. The Journal of Applied Psychology, 86, 499-512.

Dickerson, S. S., Brewer, C. S., Kovner, C., \& Way, M. (2007). Giving voice to registered nurses' decision to work. Nursing Forum, 42, $132-142$.

Edwards, J. R., \& Cooper, C. L. (1990). The person-environment fit approach to stress: Recurring problems and some suggested solutions. Journal of Organizational Behavior, 11, 293-307.

Floyd, F. J., \& Widaman, K. F. (1995). Factor analysis in the development and refinement of clinical assessment instruments. Psychological Assessment, 7, 286-299.

Griep, R. H., Rotenberg, L., Chor, D., Toivanen, S., \& Landsbergis, P. (2010). Beyond simple approaches to studying the association between work characteristics and absenteeism: Combining the DCS and ERI models. Work \& Stress, 24, 179-195.

Hakanen, J. J., Bakker, A. B., \& Schaufeli, W. B. (2006). Burnout and work engagement among teachers. Journal of School Psychology, $43,495-513$.

Hu, Q., \& Schaufeli, W. B. (2011). The convergent validity of four burnout measures in a Chinese sample: A confirmatory factor-analytic approach. Applied Psychology: An International Review, 60, 87-111.

Hu, Q., \& Schaufeli, W. B. (in press). The impact of job insecurity and current remuneration on organizational outcomes of Chinese family-owned business workers. Career Development International.

Jaccard, J., Wan, C. K., \& Turrisi, R. (1990). The detection and interpretation of interaction effects between continuous variables in multiple regression. Multivariate Behavioral Research, 25, 467-478.

Karasek, R., \& Theorell, T. (1990). Healthy work: Stress, productivity and the reconstruction of working life. New York: Basic Books.

Kasl, S. V. (1996). The influence of the work environment on cardiovascular health: A historical, conceptual, and methodological perspective. Journal of Occupational Health Psychology, 1, 42-56.

Korunka, C., Kubicek, B., \& Schaufeli, W. B. (2009). Work engagement and burnout: Testing the robustness of the Job Demands-Resources model. The Journal of Positive Psychology, 4, 243-255.

Landsbergis, P. A., \& Theorell, T. (2000). Measurement of psychosocial workplace exposure variables. Occupational Medicine State of the Art Reviews, $15,163-188$.

Llorens, S., Bakker, A. B., Schaufeli, W. B., \& Salanova, M. (2006). Testing the robustness of the Job Demands-Resources model. International Journal of Stress Management, 13, 378-391.

Marsh, H. W., Balla, J. R., \& Hau, K. T. (1996). An evaluation of incremental fit indexes: A clarification of mathematical and empirical properties. In G. A. Marcoulides \& R. E. Schumacker (Eds.), Advanced structural equation modeling techniques (pp. 315-353). Mahwah, NJ: Lawrence Erlbaum.

Ota, A., Masue, T., Yasuda, N., Tsutsumi, A., Mino, Y., \& Ohara, H. (2005). Association between psychosocial job characteristics and insomnia: an investigation using two relevant job stress models - the Demand-Control-Support (DCS) model and the Effort-Reward Imbalance (ERI) model. Sleep Medicine, 6, $353-358$.

Preckel, D., Meinel, M., Kudielka, B. M., Haug, H. J., \& Fischer, J. E. (2007). Effort-reward-imbalance, overcommitment and self-reported health: Is it the interaction that matters? Journal of Occupational and Organizational Psychology, 80, 91-107.

Salanova, M., Schaufeli, W. B., Xanthoupoulou, D., \& Bakker, A. B. (2010). Gain spirals of resources and work engagement. In A. B. Bakker \& M. P. Leiter (Eds.), Work engagement: A handbook of essential theory and research (pp. 118-131). New York: Psychology Press.

Schaufeli, W. B., \& Bakker, A. B. (2004). Job demands, job resources, and their relation with burnout and engagement: A multi-sample study. Journal of Organizational Behavior, 25, 293-315.

Schaufeli, W. B., Bakker, A. B., \& Salanova, M. (2006). The measurement of work engagement with a short questionnaire: A cross-national study. Educational and Psychological Measurement, 66, 701-716.

Schaufeli, W. B., Bakker, A. B., \& van Rhenen, W. (2009). How changes in job demands and resources predict burnout, work engagement, and sickness absenteeism. Journal of Organizational Behavior, 30, 893-917.

Schaufeli, W. B., Leiter, M. P., Maslach, C., \& Jackson, S. E. (1996). MBI-General survey. Palo Alto, CA: Consulting Psychologists Press.

Siegrist, J. (1996). Adverse health effects of high effort - Low reward conditions at work. Journal of Occupational Health Psychology, 1, $27-43$.

Siegrist, J. (2002). Effort-reward imbalance at work and health. In P. L. Perrewé \& D. C. Ganster (Eds.), Historical and current perspectives on stress and health (pp. 261-291). Amsterdam: JAI Elsevier.

Siegrist, J., Starke, D., Chandola, T., Godin, I., Marmot, M., Niedhammer, I., et al. (2004). The measurement of effort-reward imbalance at work. Social Science E Medicine, 58, 1483-1499.

Stansfeld, S. A., North, F. M., White, I., \& Marmot, M. G. (1995). Work characteristics and psychiatric disorder in civil servants in London. Journal of Epidemiology and Community Health, 49, 48-53.

Taris, T. W. (2006). Bricks without clay: On urban myths in occupational health psychology. Work \& Stress, $20,99-104$.

Theorell, T., \& Karasek, R. (1996). Current issues relating to psychosocial job strain and cardiovascular disease research. Journal of Occupational Health Psychology, 1 , $9-26$.

Van de Ven, B., Vlerick, P., \& De Jonge, J. (2008). The interplay of job demands, job resources and cognitive outcomes in informatics. Stress and Health, $24,375-382$.

Van den Tooren, M., \& De Jonge, J. (2008). Managing job stress in nursing: What kind of resources do we need? Journal of Advanced Nursing, $63,75-84$.

Van Vegchel, N., De Jonge, J., \& Landsbergis, P. A. (2005). Occupational stress in (inter)action: The interplay between job demands and job resources. Journal of Organizational Behavior, 26, 535-560.

Van Veldhoven, M., De Jonge, J., Broersen, S., Kompier, M., \& Meijman, T. (2002). Specific relations between psychosocial job conditions and job-related stress: A three-level analytic approach. Work \& Stress, 16, 207-228.

Zheng, Y. P., Hu, Q., Xu, Y. L., \& He, Y. Z. (2010). A survey on work engagement among clinical nurses. Chinese Journal of Practical Nursing, 6, $74-75$. 